UDC 616.24-008.4

\title{
CLINICAL EFFECTIVENESS OF COMPLEX LONG-TERM THERAPY IN PATIENTS WITH CHRONIC OBSTRUCTIVE PULMONARY DISEASE
}

Kulik E.G., Pavlenko V.I., Naryshkina S.V.

Amur State Medical Academy, Blagoveshchensk, Russia

Aim of studies: evaluate the action of complex therapy with rophlumilast on clinical course in the patients with COPD of C, D types during a year.

Materials and methods 69 patients with COPD of high risk (GOLD, 2011) at the age of 42-75 years treated in the specialized pulmonary department from 2012 to 2015 were included. COPD was diagnosed on the ground of clinic instrumental methods of examination taking into account international and federal documents. The patients were divided in to 2 groups by the simple blind method in the dependence on the volume of administered therapy. The males ( $82,5 \%$ ) were predominated. Diagnostics of COPD were performed on the ground of clinical instrumental methods of examination taking into account the international and federal documents. The patients of the first group $(n=38)$ took the preparations of the first choice recommended GOLD (2013), in the treatment of the second group ( $n=31$ ) the drug rophlumilast ("Daxas") was added at the dosage 50ovkg once a day in the evenings daily during a year. The groups were equal to the sex, duration of COPD and case history of smoking, basic therapy. Complex clinical instrumental examinations of the patients were made in the period of randomization: initial data, in 6 and 12 months of studies.

The examination program included estimation of respiratory complaints (cough, sputum) according to the scale: 0-no symptom, 1-slight manifestation of the symptom, 2-moderate manifestation of the symptom, 3-severe manifestation of the symptom. Rate of dyspnea manifestation was evaluated due to the well-known scale mMRC (o-4 points) filled in by the patients independently.

Also a number of occurred attacks in patients in comparison with frequency ones in last year was evaluated. Control and treatment correction were performed once a month at the out-patient department.

The data obtained were processed due to program Statistica 6.1 (Statsoft). Descriptive statics presented by $95 \%$ verified interval to the mean data. Taking into consideration asymmetric distribution of signs non parametric methods of variable statistics were used: comparison of dependence choices was made with criteria by Vilcockson; comparison of independence choices was performed with U-criteria by Mann-Whitney. Critical level of significance was equal to 0,05.

Results of studies and discussion It was determined that as well as basic therapy and therapy added with rophlumilast influenced positively on clinical course of COPD that was reflected in regretting respiratory symptoms, though their dynamics was more marked in the 2nd group (Table 1). Thus, in the group of patients treated with added rophlumilast in 6 months cough decreased $21,4 \%(p<0,01)$ in comparison with initial data and there was a tendency to the decrease of sputum secretion and dyspnea.

Table 1

Dynamics of main clinical data in the groups of patients in 6 months of treatment $(\mathrm{M} \pm 95 \% \mathrm{Cl})$

\begin{tabular}{lcccc}
\hline \multirow{2}{*}{ Signs } & \multicolumn{2}{c}{ The 1st group } & The 2nd group \\
\cline { 2 - 5 } & \multicolumn{1}{c}{$\begin{array}{c}\text { Before } \\
\text { treatment }\end{array}$} & In 6 months & Before treatment & In 6 months \\
& $2,19[1,95-2,4]$ & $1,71[1,46-1,96]^{*}$ & $2,17[1,81-2,52]$ & $1,23[0,99-1,47]^{* * \# \#}$ \\
Cough & $2,32[1,88-2,76]$ & $1,58[1,26-1,91]^{* *}$ & $2,4[2,07-273]$ & $1,53[1,29-1,79]^{* * \#}$ \\
Sputum & & & & \\
& & & $2,65[2,4-2,8]$ & $1,8[1,49-2,1]^{*} \#$
\end{tabular}

Notes: a symbol * means the differences between the data in the groups before and after the treatment ( ${ }^{\star}$ p $<0,01,{ }^{* \star}$-p $\left.<0,001\right)$; symbol \# means the difference between the data of the1st and 2nd groups after the treatment (\#-p>0,05, \#\#- p<0,05).

By the end of observation period (in 12 months) manifestation of all parameters studied in comparison with the initial data decreased verified (Table 2). 
Along with it, the manifestation of dyspnea $(p<0,05)$, sputum $(p<0,05)$ and cough $(p<0,01)$ were verified less than in the group treated with standard pharmacological scheme. Frequency of acute attacks of COPD during a year was less in patients of the 2 nd group in 1,5 times than in the 1 st group ( $p<0,05)$.

Table 2

Dynamics of main clinical data in the groups of patients in 12 months of treatment $(\mathrm{M} \pm 95 \% \mathrm{Cl})$

\begin{tabular}{|c|c|c|c|c|}
\hline \multirow[t]{2}{*}{ Signs } & \multicolumn{2}{|c|}{ The $1^{\text {st }}$ group } & \multicolumn{2}{|c|}{ The $2^{\text {nd }}$ group } \\
\hline & Before treatment & In 12 months & Before treatment & In 12 months \\
\hline Cough (points) & $2,19[1,95-2,4]$ & $2,06[1,7-2,36]^{*}$ & $2,17[1,81-2,52]$ & $1,43[1,19-1,67]^{* * *} \# \#$ \\
\hline Sputum (points) & $2,32[1,88-2,76]$ & $1,84[1,55-2,12]^{*}$ & $2,4[2,07-2,73]$ & $1,67[1,42-1,92]^{* *} \#$ \\
\hline $\begin{array}{l}\text { Dyspnea according } \\
\text { to the scale mMRs } \\
\text { (points) }\end{array}$ & $2,65[2,4-2,89]$ & $2,23[1,62-2,05]^{*}$ & $2,65[2,4-2,8]$ & $1,83[1,62-2,05]^{* *} \#$ \\
\hline $\begin{array}{l}\text { Frequency of attacks } \\
\text { for a year }\end{array}$ & $2,07[1,78-2,36]$ & $1.87[1,6-2,14]^{*}$ & $2,06[1,84-2,28]$ & $1,4[1,18-1,62]^{* *} \#$ \\
\hline
\end{tabular}

Notes: symbol * means the differences before and after the treatment $\left({ }^{*}-p<0,05,{ }^{\star \star}-p<0,01 ;{ }^{* \star}-p<0,05\right)$, symbol \# means the differences between the data of the 1st and 2 nd groups after the treatment (\# -p<0,05, \#\# $-p<0,01)$.

Conclusions The data obtained are in accordance with up-to-date notions that complex therapy of COPD complemented with modern anti-inflammatory preparations is able not only to improve clinical course of COPD, its clinical signs, but decrease significantly the frequency of acute attacks of COPD that is the marker of disease severity and enhance the rate of pulmonary function decrease. Thus, our research points out to the essential anti-inflammatory action of rophlumilast and determine reasonable long-term administration of this remedy for the patients with high risk types of COPD. The question of administration of rophlumilast to the patients of lower risk type needs the further investigation.

\section{Literature}

1.Agusti A., Calverley P.M., Celli, et al. Characterisation of COPD heterogeneity in the ECLIPSE cohort // Respir Res. 2010.-11. P.122.

2.Global Initiative for Chronic Strategy for the Diagnosis, Management, and Prevention of Chronic Obstructive Pulmonary Disease. Updated 2013. www.goldcopd.com.

3. Kulik E.G., Naryshkina S.V., Pavlenko V.I. The influence of phosphodiesterase-4 inhibitor on the functional condition of vascular endothelium in patients with chronic obstructive pulmonary disease // Pacific medical journal. 2015. 4(65). P.53-55.

4.Kulik E.G., Pavlenko V.I, Naryshkina S.V. Clinical effectiveness of complex long-term therapy in patients with chronic obstructive pulmonary disease // The 13-th Sino-Russia Forum of Biomedical and Pharmaceutical Science 2016. P. 72-73.

5.Kulik E.G., Pavlenko V.I., Naryshkina S.V. The dynamics of markers of endothelial dysfunction at application of roflumilast in patients with chronic obstructive pulmonary disease // The 11th Sino-Russia Forum of Biomedical and Pharmaceutical Science The conference proceedings. 2014. P. 16-18.

6.Rybas E.G., Naryshkina S.V. To the question concerning the pathogenic treatment of chronic obstructive pulmonary disease // Amur medical journal. 2013. 2-1(2). P.105-108.

7.Pavlenko V., Naryshkina S.V. Clinical and functional course of chronic obstructive pulmonary disease associated with ischemic heart disease against the complex therapy with nebivolol // Bulletin physiology and pathology of respiration. 2012. 43. P. 34-39.

8.Sin D.D., Vestbo J. Biomarkers in chronic obstructive pulmonary disease // Proc Am Thorac Soc. 2009. Vo.6. P.543-545. 